\title{
Trabalhonecessário
}

ISSN: 1808 - 799X

ANO 12, № 19 - 2014

Memória e Documentos

\section{A EDUCAÇÃO NA CONSTITUIÇÃO DE 1934: 80 ANOS DE UM CAPÍTULO ESPECÍFICO NA CARTA MAGNA}

\author{
Francisco José da Silveira Lobo Neto
}

\section{Introdução}

A Constituição outorgada pelo primeiro Imperador, em 25 de março de $1824^{1}$, no seu último Artigo e em seus penúltimos itens, dispõe sobre a educação de uma forma quase lacônica:

\begin{abstract}
Art. 179. A inviolabilidade dos Direitos Civis, e Politicos dos Cidadãos Brazileiros, que tem por base a liberdade, a segurança individual, e a propriedade, é garantida pela Constituição do Imperio, pela maneira seguinte: [...] XXXII. A Instrucção primaria, e gratuita a todos os Cidadãos; XXXIII. Collegios, e Universidades, aonde serão ensinados os elementos das Sciencias, Bellas Letras, e Artes.
\end{abstract}

Já a República, proclamada em 15 de novembro de 1889, através do Decreto nำ 78-B, de 21 de dezembro de 1889 do Governo Provisório ${ }^{2}$, convocou para 15 de setembro de 1890 a eleição de uma Assembleia Constituinte. Reunida a partir de 15 de dezembro de 1890, denominando-se Congresso Constituinte, estabelece, decreta e promulga, em 24 de fevereiro de 1891, a Constituição dos Estados Unidos do Brasil $^{3}$. Mas, ainda não foge - no que se refere à educação de um tratamento em termos gerais no conjunto das atribuições do Congresso e no conjunto da declaração de direitos dos cidadãos brasileiros. Textualmente: 


\section{Trabalhonecessário}

ISSN: 1808 - 799X

ANO 12, № 19 - 2014

Art. 35 - Incumbe, outrossim, ao Congresso, mas não privativamente: $1^{\circ}$ ) velar na guarda da Constituição e das leis e providenciar sobre as necessidades de caráter federal;

$2^{\circ}$ ) animar no Pais o desenvolvimento das letras, artes e ciências, bem como a imigração, a agricultura, a indústria e comércio, sem privilégios que tolham a ação dos Governos locais; $3^{\circ}$ ) criar instituições de ensino superior e secundário nos Estados; 4º) prover a instrução secundária no Distrito Federal. [...]

Art. 72 - A Constituição assegura a brasileiros e a estrangeiros residentes no País a inviolabilidade dos direitos concernentes à liberdade, à segurança individual e à propriedade, nos termos seguintes: [...] $\S 6^{\circ}$ - Será leigo o ensino ministrado nos estabelecimentos públicos. $\S 7^{0}$ - Nenhum culto ou igreja gozará de subvenção oficial, nem terá relações de dependência ou aliança com o Governo da União ou dos Estados.

A primeira norma, após a Constituição Republicana ${ }^{4}$, é o Decreto nํㅜ 3.890, de $1^{\circ}$ de janeiro de 1901, quando o Governo do Presidente Campos Salles, inaugura o século XX aprovando o "Codigo dos Institutos Officiaes de Ensino

Superior e Secundario, dependentes do Ministerio da Justiça e Negocios

Interiores", cujo titular era Epitácio Pessoa, que, em 1918 se elegerá Presidente da República. Código que bem ilustra a convicção republicana da perseverante dualidade educacional porque fundamentalmente estrutural, herança do Império, já assumida no Ato Adicional e, dez anos antes, inscrita no Art. 35 da Carta Magna.

Seguem-se as reformas dos Ministros Rivadávia Corrêa (Decreto no 8.659, de 5 de abril de 1911), Carlos Maximiliano (Decreto № 11.530, de 18 de março de 1915) e João Luiz Alves (Decreto oo 16.782 A, de 13 de janeiro de 1925). Este último dedica o seu Capítulo III ao Ensino Primário. Melhor dizendo: às condições e critérios dos acordos da União, através do criado Departamento Nacional da Educação, com os Estados para, neles, "animar e promover a difusão do ensino primário". 


\section{Trabalhonecessário}

ISSN: 1808 - 799X

ANO 12, № 19 - 2014

As turbulências da Primeira República - agudamente presentes no Governo de Arthur Bernardes, com prosseguimento no Governo Washington Luís - caminharam para a instabilidade da sucessão presidencial, com a candidatura oposicionista de Getúlio Vargas, Presidente do Estado do Rio Grande do Sul, rompendo o acordo das elites de São Paulo e Minas Gerais. Hábil político, dotado de magnetismo pessoal e de propostas reformistas, mas derrotado por Júlio Prestes nas eleições, assume o poder como Chefe do Governo Provisório, após o golpe militar que depõe o Presidente Washigton Luiz. Pelo Decreto oㅜ 19.398, de 11 de novembro de 1930, em seu Art. 1ํ, o Governo Provisório passa a exercer "discricionariamente, em toda sua plenitude, as funções e atribuições, não só do Poder Executivo, como também do Poder Legislativo, até que, eleita a Assembléia Constituinte, estabeleça esta a reorganização constitucional do país" 5 .

Esta Assembléia Constituinte ${ }^{6}$, cuja eleição ocorreu em 3 de maio de 1933, recebeu o Anteprojeto de Constituição elaborado por Comissão presidida pelo Ministro da Justiça e dos Negócios Interiores em 16 de novembro de 1933. A Constituição foi proclamada em 16 de julho de 1934. E rasgada em 1937, pelo mesmo Getúlio Vargas.

\section{Documentos}

A) Decreto n 21.402, de 14 de Maio de 1932

Fixa o dia três de maio de 1933 para a realização das eleições à Assembléia Constituinte e cria uma comissão para elaborar e anteprojeto da Constituição.

O Chefe do governo Provisório da República dos Estados Unidos do Brasil: 


\section{Trabalhonecessário}

ISSN: 1808 - 799X

ANO 12, № $19-2014$

Considerando que, com a constituição dos Tribunais Eleitorais, terá início a fase de alistamento dos cidadãos para a escolha dos seus representantes na Assembleia Constituinte;

Considerando que, nesses termos, convém seja prefixado um prazo dentro no qual se habilitem a exercer o direito de voto; Considerando a utilidade de abrir desde logo, como trabalho preparatório as deliberações da Assembleia Constituinte, um largo debate nacional em torno às questões fundamentais das organizações políticas do país,

\section{DECRETA:}

Art. $1^{\circ}$ É criada, sob a presidência do Ministro da Justiça e Negócios Interiores, uma comissão incumbida de elaborar o anteprojeto da Constituição.

Art. $2^{\circ}$ A comissão será composta de tantos membros quantos forem necessários a elaboração do referido anteprojeto e por forma a serem nela representadas as correntes organizadas de opinião e de classe, a juízo do Chefe do Governo.

Art. 3ำ As eleições à Assembleia Constituinte se realizarão no dia 3 de maio de 1933, observados o decreto n.21.076 de 24 de fevereiro de 1932 e os que, em complemento dele, foram ou vierem a ser expedidos pelo Governo.

Art. 4ํㅡㄹ Revogam-se as disposições em contrário.

Rio de Janeiro, em 14 de maio de $1932,111^{\circ}$ da Independência e $4^{\circ}{ }^{\circ}$ a República.

GETULIO VARGAS

Francisco Campos; José Fernandes Leite de Castro; Oswaldo Aranha; Protogenes P. Guimarães; Afranio de Mello Franco; Joaquim Pedro Salgado Filho; Mario Barbosa Carneiro, encarregado de Expediente do Ministério da Agricultura, na, ausência do ministro; Fernando Augusto de Almeida Brandão, encarregado do 


\section{Trabalhonecessário}

ISSN: 1808 - 799X

ANO 12, № 19 - 2014

Expediente na ausência do ministro da Viação e Obras Públicas. B) Constituição da República dos Estados Unidos do Brasil, de 16 de julho de 1934. TíTULO V Da Família, da Educação e da Cultura; CAPÍTULO II Da Educação e da Cultura (Art. $\underline{148-158)}$

"Nós, os representantes do povo brasileiro, pondo a nossa confiança em Deus, reunidos em Assembléia Nacional Constituinte para organizar um regime democrático, que assegure à Nação a unidade, a liberdade, a justiça e o bemestar social e econômico, decretamos e promulgamos a seguinte CONSTITUIÇÃO DA REPÚBLICA DOS ESTADOS UNIDOS DO BRASIL

$[\ldots]$

TíTULO V Da Família, da Educação e da Cultura

$[\ldots]$

\section{CAPÍTULO II Da Educação e da Cultura}

Art 148 - Cabe à União, aos Estados e aos Municípios favorecer e animar o desenvolvimento das ciências, das artes, das letras e da cultura em geral, proteger os objetos de interesse histórico e o patrimônio artístico do País, bem como prestar assistência ao trabalhador intelectual.

Art 149 - A educação é direito de todos e deve ser ministrada, pela família e pelos Poderes Públicos, cumprindo a estes proporcioná-la a brasileiros e a estrangeiros domiciliados no País, de modo que possibilite eficientes fatores da vida moral e econômica da Nação, e desenvolva num espírito brasileiro a consciência da solidariedade humana.

Art 150 - Compete à União:

a) fixar o plano nacional de educação, compreensivo do ensino de todos os graus e ramos, comuns e especializados; e coordenar e fiscalizar a sua execução, 


\section{Trabalhonecessário}

ISSN: 1808 - 799X

\section{ANO 12, № 19 - 2014}

em todo o território do País;

b) determinar as condições de reconhecimento oficial dos estabelecimentos de ensino secundário e complementar deste e dos institutos de ensino superior, exercendo sobre eles a necessária fiscalização;

c) organizar e manter, nos Territórios, sistemas educativos apropriados aos mesmos;

d) manter no Distrito Federal ensino secundário e complementar deste, superior e universitário;

e) exercer ação supletiva, onde se faça necessária, por deficiência de iniciativa ou de recursos e estimular a obra educativa em todo o País, por meio de estudos, inquéritos, demonstrações e subvenções.

Parágrafo único - O plano nacional de educação constante de lei federal, nos termos dos arts. 5, no XIV, e 39, nํㅛ 8, letras a e e, só se poderá renovar em prazos determinados, e obedecerá às seguintes normas:

a) ensino primário integral gratuito e de freqüência obrigatória extensivo aos adultos;

b) tendência à gratuidade do ensino educativo ulterior ao primário, a fim de o tornar mais acessível;

c) liberdade de ensino em todos os graus e ramos, observadas as prescrições da legislação federal e da estadual;

d) ensino, nos estabelecimentos particulares, ministrado no idioma pátrio, salvo o de línguas estrangeiras;

e) limitação da matrícula à capacidade didática do estabelecimento e seleção por meio de provas de inteligência e aproveitamento, ou por processos objetivos apropriados à finalidade do curso; 


\section{Trabalhonecessário}

ISSN: 1808 - 799X

ANO 12, № 19 - 2014

f) reconhecimento dos estabelecimentos particulares de ensino somente quando assegurarem a seus professores a estabilidade, enquanto bem servirem, e uma remuneração condigna.

Art 151 - Compete aos Estados e ao Distrito Federal organizar e manter sistemas educativos nos territórios respectivos, respeitadas as diretrizes estabelecidas pela União.

Art 152 - Compete precipuamente ao Conselho Nacional de Educação, organizado na forma da lei, elaborar o plano nacional de educação para ser aprovado pelo Poder Legislativo e sugerir ao Governo as medidas que julgar necessárias para a melhor solução dos problemas educativos bem como a distribuição adequada dos fundos especiais.

Parágrafo único - Os Estados e o Distrito Federal, na forma das leis respectivas e para o exercício da sua competência na matéria, estabelecerão Conselhos de Educação com funções similares às do Conselho Nacional de Educação e departamentos autônomos de administração do ensino.

Art 153 - O ensino religioso será de freqüência facultativa e ministrado de acordo com os princípios da confissão religiosa do aluno manifestada pelos pais ou responsáveis e constituirá matéria dos horários nas escolas públicas primárias, secundárias, profissionais e normais.

Art 154 - Os estabelecimentos particulares de educação, gratuita primária ou profissional, oficialmente considerados idôneos, serão isentos de qualquer tributo.

Art 155 - É garantida a liberdade de cátedra.

Art 156 - A União e os Municípios aplicarão nunca menos de dez por cento, e os Estados e o Distrito Federal nunca menos de vinte por cento, da renda resultante dos impostos na manutenção e no desenvolvimento dos sistemas edu- 


\section{Trabalhonecessário}

ISSN: 1808 - 799X

\section{ANO 12, № 19 - 2014}

cativos.

Parágrafo único - Para a realização do ensino nas zonas rurais, a União reservará no mínimo, vinte por cento das cotas destinadas à educação no respectivo orçamento anual.

Art 157 - A União, os Estados e o Distrito Federal reservarão uma parte dos seus patrimônios territoriais para a formação dos respectivos fundos de educação.

$\S 1^{\circ}$ - As sobras das dotações orçamentárias acrescidas das doações, percentagens sobre o produto de vendas de terras públicas, taxas especiais e outros recursos financeiros, constituirão, na União, nos Estados e nos Municípios, esses fundos especiais, que serão aplicados exclusivamente em obras educativas, determinadas em lei.

$\S 2^{\circ}$ - Parte dos mesmos fundos se aplicará em auxílios a alunos necessitados, mediante fornecimento gratuito de material escolar, bolsas de estudo, assistência alimentar, dentária e médica, e para vilegiaturas.

Art 158 - É vedada a dispensa do concurso de títulos e provas no provimento dos cargos do magistério oficial, bem como, em qualquer curso, a de provas escolares de habilitação, determinadas em lei ou regulamento.

$\S 1^{\circ}$ - Podem, todavia, ser contratados, por tempo certo, professores de nomeada, nacionais ou estrangeiros.

$\S 2^{\circ}$ - Aos professores nomeados por concurso para os institutos oficiais cabem as garantias de vitaliciedade e de inamovibilidade nos cargos, sem prejuízo do disposto no Título VII. Em casos de extinção da cadeira, será o professor aproveitado na regência de outra, em que se mostre habilitado". 


\section{Trabalhonecessário}

ISSN: 1808 - 799X

ANO 12, № 19 - 2014

1 Disponível em http://www.planalto.gov.br/ccivil_03/constituicao/constituicao24.htm acesso em setembro de 2014.

2 Disponível em http://www2.camara.leg.br/legin/fed/decret/1824-1899/decreto-78-b-21-dezembro1889-517756-publicacaooriginal-1-pe.html, acesso em setembro de 2014.

3 Disponível em http://www.planalto.gov.br/ccivil_03/constituicao/Constituicao91.htm, acesso em setembro de 2014.

${ }^{4}$ Benjamin Constant Botelho de Magalhães, Ministro da Instrucção, Correios e Telégraphos do Governo Provisório, já com a Assembléia Constituinte eleita, através do Decreto no 981, de 8 de novembro de 1890, empreendeu a regulamentação da "Instrucção primária e secundária do Districto Federal".

5 Disponível em http://legis.senado.gov.br/legislacao/ListaPublicacoes.action?id=37246\& , acesso em setembro de 2014

${ }^{6}$ Para aprofundamento, sugere-se a leitura do insuperado livro organizado por Osmar FÁVERO,

"A Educação nas Constituintes Brasileiras 1823-1988" (Campinas, SP. Editora Autores Associados, 2001). 